Revista Brasileira de Informática na Educação - RBIE Brazilian Journal of Computers in Education (ISSN online: 2317-6121; print: 1414-5685)

http://br-ie.org/pub/index.php/rbie

\title{
Capacitando Professores no Programa Norte-rio-grandense de Pensamento Computacional
}

\author{
Title: Empowering Teachers in the Norte-rio-grandense Program of Computational Thinking
}

\author{
Jeanne da Silva Barbosa Bulcão \\ Instituto Metrópole Digital \\ Universidade Federal do Rio Grande do Norte \\ jeannebulcao1@gmail.com \\ Carlos Artur Santos Guimarães \\ Instituto Metrópole Digital \\ Universidade Federal do Rio Grande do Norte \\ arturguimaraes@gmail.com
}

\author{
Charles Andryê Galvão Madeira \\ Instituto Metrópole Digital \\ Universidade Federal do Rio Grande do Norte \\ charles@imd.ufrn.br \\ Crisiany Alves de Sousa \\ Instituto Metrópole Digital \\ Universidade Federal do Rio Grande do Norte \\ crisianyalves@gmail.com
}

\begin{abstract}
Resumo
A sociedade contemporânea tem experimentado mudanças e transformações provocadas pelos avanços cientificos e tecnológicos que afetam e modificam o mundo do trabalho, as relações sociais, a cultura, a ciência e a educação. Entretanto, chama atenção o fato da Educação Básica brasileira ainda não estar alinhada a esta tendência mundial e apenas ensaiar experiências de integração das tecnologias digitais na rotina das escolas públicas. Isso se deve, em parte, à formação inicial dos professores que pouco contempla o uso pedagógico das tecnologias digitais no processo de ensino e de aprendizagem. Além disso, também torna-se cada vez mais necessário incentivar práticas educativas que estimulem habilidades relacionadas à capacidade de resolver problemas, lidar com frustrações e criar soluções como condições essenciais para que as pessoas possam se desenvolver integralmente e profissionalmente, permitindo o ingresso e a manutenção em um mundo do trabalho que está em constante evolução. Neste sentido, uma direção que vem se popularizando e tem incentivado o aparecimento de um grande número de iniciativas relacionadas ao uso das tecnologias digitais na educação é a do Pensamento Computacional. É nesta direção que se insere o presente artigo, que tem como objetivo relatar a experiência de um curso de formação continuada em Pensamento Computacional do Programa Norte-rio-grandense de Pensamento Computacional (Pensa RN), realizado com professores dos anos finais do Ensino Fundamental. Esse curso une as metodologias da aprendizagem baseada em resolução de problemas, computação desplugada, jogos digitais e programação visual, a fim de estimular o desenvolvimento do Pensamento Computacional como um instrumento de aumento do poder cognitivo e operacional humano, integrando-o nas práticas pedagógicas dos professores. Como resultados da experiência, os professores adotaram novas estratégias no seu ambiente de trabalho, elaborando e aplicando práticas educativas integradas ao Pensamento Computacional em escolas públicas da rede de ensino.
\end{abstract}

Palavras-Chave: Formação Continuada, Ensino Fundamental, Pensamento Computacional, Metodologias Ativas.

\begin{abstract}
Contemporary society has for some time experienced changes and transformations due to scientific and technological advances that affect and modify the labor market, social relations, culture, science and education. However, it is noteworthy that Brazilian Basic Education is not yet in line with this global trend and is still rehearsing experiences of integrating digital technologies into the routine of public schools. This is a consequence of initial training of teachers, which inserts little pedagogical use of digital technologies in the teaching and learning process. In addition, it is also increasingly necessary to encourage educational practices that train skills related to problem solving, deal with frustrations and create solutions as essential conditions for fully and professionally people development. In this sense, a direction that has become popular in recent years and has encouraged the emergence of a large number of initiatives related to the use of digital technologies in education is that of Computational Thinking. This paper aims to report the experience of a continuing education course in Computational Thinking of the Norte-rio-grandense Program of Computational Thinking (Pensa RN), that is focused on elementary school teachers. This course associates several methodologies, such as problem-based learning, Computer Science unplugged, digital games and Cite as: Bulcão, J. S. B, Madeira, C. A. G, Guimarães, C. A. S., \& Sousa, C. A. (2021). Capacitando Professores no Programa Norte-rio-grandense de Pensamento Computacional. Revista Brasileira de Informática na Educação, 29, 1178-1201. DOI: 10.5753/rbie.2021.2120
\end{abstract}


visual programming, in order to promote the development of Computational Thinking as an instrument to increase human cognitive and operational power, integrating it into the pedagogical practices of the teachers. As a result of the course application, teachers adopted new strategies in their work environment, developing and applying educational practices by integrating Computational Thinking in public schools.

Keywords: Continuing Education, Elementary Education, Computational Thinking, Active Methodologies.

\section{Introdução}

Apesar de vivermos numa sociedade na qual os profissionais das mais diversas áreas passam grande parte do seu tempo utilizando computadores, a Educação Básica brasileira ainda caminha para efetivar práticas de integração das tecnologias digitais na rotina das escolas. Para que ocorra essa integração, é necessário repensar a formação inicial dos professores e proporcionar formações continuadas que contemplem o uso pedagógico das tecnologias digitais para os processos de ensino e aprendizagem (Almeida \& Valente, 2011). A questão é que as novas formas de produção e disponibilização do conhecimento estão provocando profundas mudanças na maneira de ensinar e de aprender, criando um novo universo para o ecossistema da educação. Portanto, para acompanhar as mudanças e evoluções da sociedade, é necessário haver um enriquecimento escolar para dar espaço ao uso das tecnologias digitais e proporcionar a inovação e a melhoria dos processos de ensino e de aprendizagem, ensinando aos jovens alunos que as tecnologias digitais também servem para produzir conhecimento novo e novas tecnologias (Raabe et al., 2016).

É neste contexto que se insere o Programa de Inovação Educação Conectada do Ministério da Educação (MEC, 2018), que recentemente se tornou política por meio da Lei No 14.180 de 01 de julho de 2021 (DOU, 2021), e tem como objetivo apoiar a universalização do acesso à internet de alta velocidade, formar professores e gestores e fomentar o uso dos recursos educacionais digitais na Educação Básica. Além disso, a Base Nacional Comum Curricular (BNCC), que é um documento normativo das aprendizagens essenciais a serem desenvolvidas pelos estudantes ao longo das etapas e modalidades da Educação Básica, apresenta dez competências gerais que abrangem desde a Educação Infantil até o Ensino Médio (MEC, 2017). Dentre essas competências gerais, está a competência de cultura digital, que visa estimular práticas relacionadas à compreensão, utilização e criação de Tecnologias Digitais da Informação e Comunicação para o exercício da cidadania e para a resolução de problemas.

É nesse sentido que nos últimos anos tem emergido um volume significativo de iniciativas com vistas ao uso das metodologias ativas e das tecnologias digitais na educação, como é o caso do Pensamento Computacional (Wing, 2006) que se mostra como uma abordagem geral para resolução de problemas e conta com o desenvolvimento de um corpo de pesquisas mundialmente robusto (Avila et al, 2016; Zanetti \& Oliveira, 2015; De Paula, Valente \& Burn, 2014). O Pensamento Computacional (PC) ajuda a ensinar os indivíduos a pensar mais eficazmente pelo fato de formalizar a concepção de sistemas e trabalhar na compreensão do comportamento humano, se mostrando como habilidades bastante relevantes para as mais diversas profissões.

Portanto, é vital para o desenvolvimento do país que o PC seja fomentado nas escolas da Educação Básica, promovendo a alfabetização tecnológica dos jovens a partir do desenvolvimento de práticas que permitam o acesso, produção e reflexão sobre as tecnologias digitais, conforme indicam as Diretrizes para Ensino de Computação na Educação Básica da Sociedade Brasileira de Computação (SBC, 2017) e o Currículo de Referência em Tecnologia e Computação do Centro de Inovação para a Educação Brasileira (CIEB, 2018).

Esses documentos de referência têm como objetivo oferecer diretrizes e orientações para apoiar as redes de ensino e escolas a incluírem os temas tecnologia e computação em suas propostas curriculares. Para tanto, as habilidades propostas no currículo de referência estão 
diretamente associadas às competências gerais e habilidades da BNCC e apresentam sugestões de recursos e materiais que podem ser utilizados pelos professores para aplicar o pensamento computacional em suas ações pedagógicas, além de contribuir para disseminação de práticas pedagógicas integradas ao PC nas escolas públicas e privadas. Tal integração entre o ensino do PC e os conteúdos formativos através das tecnologias digitais pode contribuir para a melhoria dos indicadores educacionais e a atualização da formação dos alunos.

Logo, torna-se necessário e urgente a oferta de cursos de formação continuada que ofereçam subsídios para o desenvolvimento de novos conhecimentos por parte dos professores e alunos, em um contexto de aprendizagem mão na massa no qual possibilite o exercício e a aplicação dos novos conhecimentos na prática pedagógica. Estes cursos devem ser pautados na dinâmica e nas necessidades advindas do trabalho cotidiano dos professores nos ambientes das instituições de ensino, de modo a fortalecê-los no enfrentamento dos desafios postos por esse trabalho, conforme é apontado na Base Nacional Comum para a Formação Continuada de Professores da Educação Básica (BNC-Formação Continuada) (DOU, 2020). Para isso, parte da compreensão de que a aquisição e a construção de conhecimento pelos sujeitos são potencializadas por meio de um processo de aprendizagem participativo e significativo, possibilitando a todos os envolvidos se perceberem a atuarem como autores do conhecimento, tornando a instituição de ensino e a sala de aula espaços de discussões, pesquisas e descobertas.

É nesse contexto que este trabalho se insere relatando uma experiência concreta de formação continuada de professores voltada ao desenvolvimento do PC. Essa formação se caracteriza como uma iniciativa do Programa Norte-rio-grandense de Pensamento Computacional (Pensa RN), que visa criar uma cultura de integração do Pensamento Computacional nas dinâmicas das ações pedagógicas das escolas do Ensino Básico. Isso envolve desde uma mudança nas práticas educativas dos professores até a criação de clubes de programação nas escolas.

\section{Fundamentação Teórica}

A sociedade contemporânea conectada e em rede tem exigido habilidades e competências relacionadas à capacidade de aprender de forma contínua, com resiliência, autonomia, criatividade e criticidade, além de resolver problemas complexos. O relatório sobre o futuro dos empregos do Fórum Econômico Mundial aponta a necessidade de um novo paradigma para a educação, no qual os estudantes possam aprender a conhecer, a fazer, a ser e conviver, adquirindo habilidades importantes para a vida (WEF, 2020). Por isso, o modelo de escola e de ensino conteudista e descontextualizado, centrado na organização do trabalho da sociedade industrial, não mais atende as necessidades dos profissionais imigrantes digitais e, tampouco, dos estudantes nativos digitais (Prensky, 2001).

A BNCC se insere nesse contexto como uma política pública para trabalhar essas competências e habilidades e estimular o desenvolvimento dos estudantes de forma integral, com vistas a estimular projetos envolvendo a cognição, a empatia, a cooperação, a criatividade e a resolução de problemas nas escolas. Para a BNCC, a escola deve inserir a cultura digital a partir do uso de tecnologias digitais físicas e simbólicas, para promoção de novos saberes relacionados à temática, no sentido de conduzir o discente para apropriação de recursos tecnológicos que o permita compreender, utilizar e criar tecnologias digitais, estimulando assim o PC (MEC, 2017).

$\mathrm{Na} \mathrm{BNCC}$, o PC se restringe ao ensino da Matemática, mas o fato do documento trazer na quinta competência geral a importância de trabalhar com a resolução de problemas, provoca a necessidade de pensar em estratégias sólidas e consolidadas que possam ser utilizadas para trabalhar essas e outras competências com os estudantes de uma forma interdisciplinar. Essa orientação da BNCC está amparada em todo um referencial teórico que surgiu com o trabalho de 
pesquisadores que buscavam modificar não apenas as práticas pedagógicas dos docentes, mas estimular um novo paradigma de ensino e aprendizagem, iniciando com a inclusão dos primeiros computadores na educação (Valente, 1997).

Um grande exemplo desses pesquisadores consiste em Seymour Papert, do Instituto de Tecnologia de Massachusetts, que desde a década 1960 realizou estudos incentivando o uso do computador pelas crianças para aprender a lógica computacional (Papert, 1994). Nas últimas décadas, pesquisadores e professores têm validado as ideias de Papert com iniciativas que visam estimular e disseminar o ensino de programação em escolas privadas e públicas em diversos países, incentivando o desenvolvimento de soluções globais e de grande impacto como é o caso da plataforma da Hora do Código (Cavalcante et al., 2016), assim como as ideias da Aprendizagem Criativa de Resnick (2020).

Atualmente, o ensino de lógica de programação tem sido superado pelas discussões sobre a necessidade de incentivar o desenvolvimento do PC. Segundo Wing (2006), o PC é uma habilidade importante e necessária para todas as profissões, não servindo apenas para os Cientistas da Computação. Portanto, deve ser ensinado em todos os níveis de ensino. Neste contexto, Blikstein (2008) acrescenta que o desenvolvimento do Pensamento Computacional é necessário para que as crianças e jovens possam, no futuro, exercer sua cidadania em plenitude.

Constata-se que o apelo mundial caminha no sentido de levar as habilidades do século XXI para as salas de aula, exigindo uma adaptação dos espaços escolares para a inserção de novas metodologias e formação continuada dos professores adequada a esta nova ecologia educacional. Com isso, a escola deve cada vez mais estar alinhada às necessidades dos estudantes deste século, no sentido de não mais democratizar o conhecimento historicamente sistematizado, mas de formar os estudantes para o livre exercício da cidadania, desenvolvendo habilidades e competências para a criação da sua identidade planetária, solucionar problemas, promover a transformação no campo social e no mundo do trabalho, para a construção de uma sociedade colaborativa e com equidade.

Para que os estudantes possam conhecer e desenvolver as habilidades relacionadas à resolução de problemas, criatividade, exercitar o pensamento e a imaginação, é preciso repensar as formações dos professores. Portanto, é importante que o desenvolvimento dessas habilidades seja estimulado nos cursos de formação para que haja aplicação nas práticas de ensino e aprendizagem, fazendo os professores darem respostas adequadas ao contexto atual que a educação contemporânea exige. Logo, é necessário que as formações iniciais e as formações continuadas possibilitem aos professores desenvolverem as habilidades, as competências e os saberes docentes necessários à educação atual e do futuro (Morin, 2016; DOU 2020).

Ao longo dos anos, inúmeras formações continuadas de professores foram realizadas. $\mathrm{Na}$ contemporaneidade, outras têm surgido com vistas a preparar os professores para atuarem no enfrentamento das não aprendizagens dos estudantes e na inclusão das tecnologias digitais nas suas práticas pedagógicas (Almeida \& Valente, 2011). Talvez pelo modelo utilizado, as formações de professores parecem ter dificuldade em fazer os professores aplicarem o conhecimento adquirido no dia-a-dia dos seus respectivos ambientes de trabalho, o que é indicado pela falta de evidências de novas estratégias didáticas nas práticas pedagógicas dos docentes. Além disso, 65\% dos docentes pesquisados pelo Comitê Gestor da Internet no Brasil (CGI, 2018) indicaram ter buscado formação continuada para uso das tecnologias digitais em suas áreas de atuação. Ademais, a pandemia da Covid-19 deixou claro que existe uma grande fragilidade na formação dos professores com o trato das tecnologias digitais (Almeida, 2020).

Destaca-se que, apesar de essas formações terem contribuído em algum grau com as novas aprendizagens para os professores, principalmente nos aspectos pedagógicos de como ensinar, elas não conseguiram estimular processos de aprendizagem tal qual se espera para os estudantes, tais como aprender a aprender, desenvolver a resiliência, o pensamento crítico e a criatividade, 
que se mostram como habilidades importantes que poderiam ser estimuladas a partir de práticas envolvendo o PC (Valente, 2016, 2019). Portanto, as formações continuadas devem perseguir práticas reflexivas, mas que também provoquem maturidade e habilidades de resiliência sobre os desafios da profissão e a necessidade de aprender continuamente.

Para Almeida e Valente (2012) o domínio de uma técnica apenas acontece por influência de uma necessidade pedagógica, o que indica a necessidade de inserir os professores em contextos de aprendizagem em que estes possam ir construindo o conhecimento a partir de sua prática pedagógica. Portanto, para que os professores possam estimular o PC junto aos estudantes, será necessário formá-los para uma mudança de mentalidade sobre suas capacidades frente às condições de escassez tecnológica e para o conhecimento sobre o que, porque, para que, e como aplicar o PC no processo de ensino e aprendizagem.

Para que ocorram práticas educativas nas escolas envolvendo o $\mathrm{PC}$, primeiramente é necessário que os professores compreendam e dominem as formas sistematizadas e dialéticas da organização desse conhecimento, que estão presentes como resultado do ensino no pensamento ou nas ações práticas dos discentes em relação ao PC (Núnez et. al, 2009). Os docentes precisam compreender o que é e como aplicar o PC na prática, considerando suas dimensões relativas à abstração, decomposição, reconhecimento de padrões e algoritmos, para que possam integrá-los à sua prática no dia-a-dia (Valente, 2016).

Nessa perspectiva, os conhecimentos relacionados ao PC podem ser estimulados através do framework chamado TPACK (sigla em inglês para Technological Pedagogical Content Knowledge), que refere-se ao conhecimento pedagógico tecnológico do conteúdo (Mishra \& Koehler, 2006), unindo diversos conhecimentos necessários conforme apresentado na Figura 1.

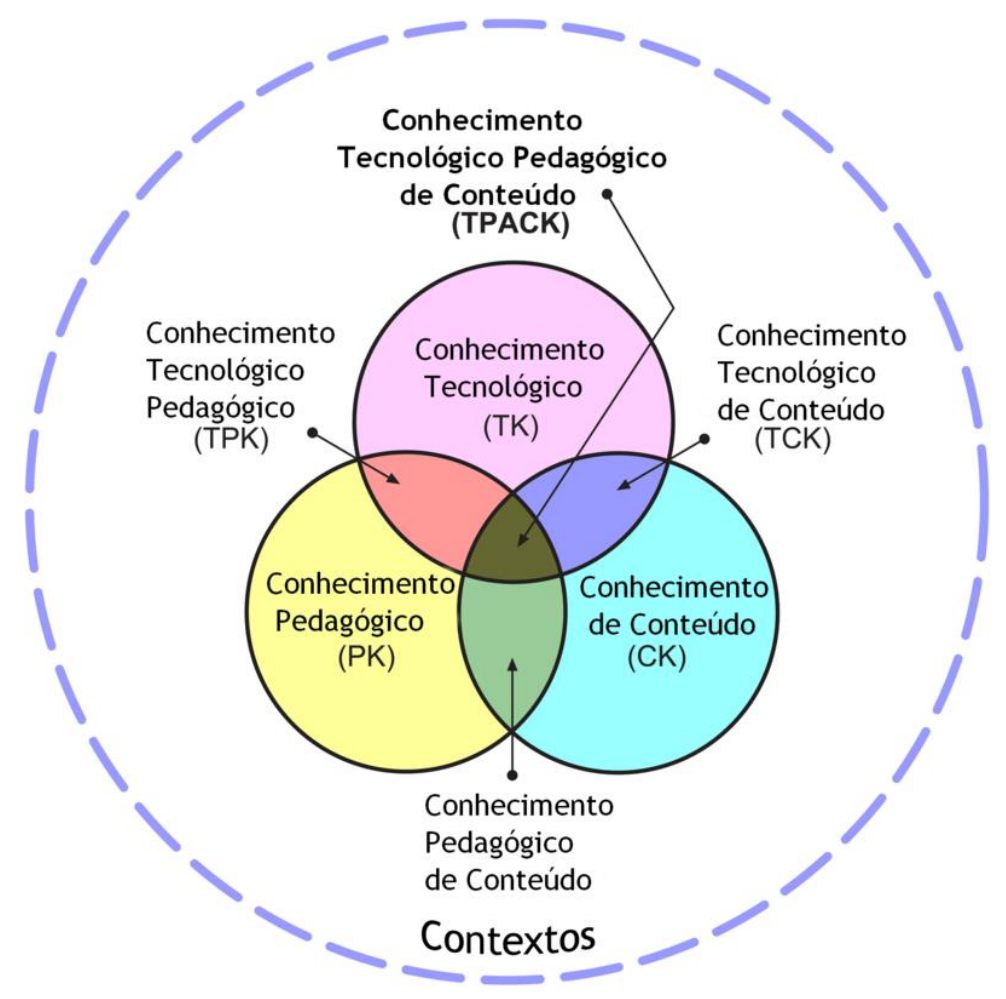

Figura 1: Framework TPACK. Fonte: http://tpack.org

O TPACK sistematiza os três principais conhecimentos que devem estar intimamente relacionados às práticas e ações nas formações para que o professor tenha subsídios necessários para compreender, selecionar e desenvolver práticas integradas ao PC, conforme detalhado na Tabela 1. Os trabalhos de Giannakos (et al., 2014), Kretzer (2019), Rocha e Prado (2018) 
apresentam resultados positivos na utilização deste framework para organização dos currículos e práticas, seleção de materiais e estratégias formativas envolvendo professores e o PC, estimulando competências de curadoria, criação e compartilhamento de práticas no tema.

Tabela 1 - Conhecimentos no TPACK e suas características. Fonte: Mishra \& Koehler (2006).

\begin{tabular}{l|l}
\hline Conhecimentos & Descrição \\
\hline $\begin{array}{l}\text { Conhecimento do } \\
\text { Conteúdo (CK) }\end{array}$ & $\begin{array}{l}\text { Conhecimento e compreensão dos assuntos ensinados, incluindo os conceitos, teorias e } \\
\text { procedimentos dentro de uma área; estruturas explicativas que organizam e conectam } \\
\text { ideias. }\end{array}$ \\
\hline $\begin{array}{l}\text { Conhecimento } \\
\text { Pedagógico (PK) }\end{array}$ & $\begin{array}{l}\text { Conhecimento sobre os processos e práticas ou métodos de ensino e aprendizagem; inclui } \\
\text { técnicas para usar na sala de aula; a natureza do público alvo; estratégias para avaliar e } \\
\text { compreender o aluno. }\end{array}$ \\
\hline $\begin{array}{l}\text { Conhecimento } \\
\text { Tecnológico (TK) }\end{array}$ & $\begin{array}{l}\text { Conhecimento sobre tecnologias padrão, tais como livros, giz e quadro negro, e tecnologias } \\
\text { mais avançadas, como a internet e vídeo digital; envolve as competências necessárias para } \\
\text { operar tecnologias específicas. }\end{array}$ \\
\hline
\end{tabular}

Segundo Mishra \& Koehler (2006), a interseção entre esses conhecimentos mobiliza novos conhecimentos, sinalizando a construção de características integrativas para a aprendizagem da docência. Na Tabela 2, vê-se de forma resumida as interseções possíveis desse modelo, evidenciando também o que se deve estimular para mobilizar nos docentes o desenvolvimento de competências profissionais sobre o tema em questão.

Tabela 2: Interseções do conhecimento do TPACK e suas características. Fonte: Mishra \& Koehler (2006).

\begin{tabular}{l|l}
\hline Conhecimentos & Descrição \\
\hline $\begin{array}{l}\text { Conhecimento } \\
\text { Pedagógico e do } \\
\text { Conteúdo (PCK) }\end{array}$ & $\begin{array}{l}\text { Inclui as abordagens de ensino que dialogam com o conteúdo e como os elementos do } \\
\text { conteúdo podem ser organizados para uma melhor prática de ensino e aprendizagem; } \\
\text { estratégias de ensino que incorporam representações conceituais, a fim de abordar as } \\
\text { dificuldades e promover uma compreensão significativa. }\end{array}$ \\
\hline $\begin{array}{l}\text { Conhecimento } \\
\text { Tecnológico e do }\end{array}$ & $\begin{array}{l}\text { Conhecimento sobre a maneira na qual a tecnologia e o conteúdo estão reciprocamente } \\
\text { relacionados; precisa-se saber não apenas o assunto que ensina, mas também a maneira } \\
\text { pela qual os conteúdos podem ser melhor explorados a partir de uma tecnologia. }\end{array}$ \\
\hline $\begin{array}{l}\text { Conhecimento } \\
\text { Tecnológico e } \\
\text { Pedagógico (TPK) }\end{array}$ & $\begin{array}{l}\text { Conhecimento sobre a existência e a capacidade das variadas tecnologias e de seu } \\
\text { potencial pedagógico; formas de uso no ensino e na aprendizagem, compreendendo como } \\
\text { ensinar aos alunos; capacidade de escolher uma ferramenta com base em sua adequação e } \\
\text { estratégias para fazer uso. }\end{array}$ \\
\hline
\end{tabular}

O modelo teórico TPACK é, portanto, a integração entre todos os conhecimentos sobre o tema objeto do conhecimento a ser explorado, constituindo-se então no conhecimento tecnológico pedagógico do conteúdo. Esse conhecimento tem como principais características a compreensão das formas de representação de conceitos usando tecnologias, considerando os aspectos pedagógicos que usam tecnologias de maneira construtiva para ensinar determinado conceito ou técnicas. Dessa forma, o modelo aponta os conhecimentos relacionados ao PC que devem ser trabalhados com os professores e evidencia um caminho positivo para a seleção dos saberes, conceitos, materiais, recursos e técnicas referentes a este conhecimento, dialogando com as dimensões do trabalho docente. Por esta razão, pode servir para organização e sistematização de uma proposta de curso de formação, oficina ou mesmo workshop, que se pretenda estimular determinado conhecimento docente. 


\section{Trabalhos Relacionados}

Iniciativas alinhadas aos programas ou projetos educacionais municipais e estaduais para integração do PC nas práticas docentes, visando a formação de professores neste tema, ainda são incipientes no Brasil. Isto ocorre na contramão do número de pesquisas sobre a temática, que tem crescido vertiginosamente desde a publicação do artigo de Wing (2006).

Por outro lado, são muitos os estudos que relatam experiências formativas em PC com professores e alunos e que apontam resultados significativos no desenvolvimento de habilidades e competências para resolução de problemas e de aumento do poder cognitivo, da capacidade criativa e da resiliência.

Dentre essas pesquisas, diversos trabalhos (Silva, Silva, \& França, 2017; Barcelos, Bortoletto, \& Andrioli, 2016; Mandaji et al., 2018) apresentam propostas semelhantes entre si, no sentido de disseminar e integrar o Pensamento Computacional nas práticas educativas dos professores. Os dois primeiros trabalhos ocorrem por iniciativas de instituições de ensino superior, sendo vinculados à disciplina de estágio docente ou curso de extensão universitária. O terceiro trabalho apresenta uma proposta mais semelhante à formação ora descrita neste artigo, visto que ele descreve uma proposta presencial, sendo uma iniciativa mobilizada em parceria entre uma universidade e uma secretaria de educação do estado. As duas primeiras iniciativas apresentam uma organização modular, com o ensino de linguagem de programação visual para criação e desenvolvimento de jogos digitais. Embora semelhante às demais iniciativas no aspecto da organização, a terceira iniciativa inclui práticas plugadas e desplugadas que utilizam fortemente a análise de micromundos, como aquelas vistas em Papert (1994) para desenvolvimento de ideias e reflexões acerca do que é o PC e como integrá-lo no processo de ensino e aprendizagem.

Para além desses trabalhos, o Programa de Inovação Educação Conectada, por meio da plataforma virtual de aprendizagem AVAMEC do Ministério da Educação - MEC, também tem fornecido formações continuadas no tema do PC. No modelo do AVAMEC, diferentemente dos demais cursos de formação, não são apresentados os objetivos, os saberes e as competências relacionadas ao PC a serem desenvolvidos pelos professores. O curso possui estratégias semelhantes a uma das metodologias utilizadas no âmbito do Projeto Programaê, apresentado por Mandaji et al. (2018) em relação a análise de situações-problemas e análises de micromundos. Nessas estratégias, os professores precisam oferecer uma resolução para a situação-problema apresentada no módulo ou oficina.

Essas iniciativas de formação continuada apresentam um design de aprendizagem que se volta a um modelo de formação centrada apenas na aprendizagem de novos conhecimentos e saberes sobre o PC. Embora relevantes, essas formações deixam secundarizados aspectos sobre o desenvolvimento profissional em que a aprendizagem da docência perpassa por uma ação profunda e sistematizada, orientada para a mudança do professor como profissional, incluindo não apenas o saber, mas também o saber fazer, o ser, e o saber pensar (Ramalho, 2013). Dessa maneira, a formação continuada precisa ser mais que instrução ou aquisição de conhecimento, visto que inclui interesses, intenções, motivações, capacidades, condutas, atitudes, valores, dentre outros elementos, que levam ao desenvolvimento profissional dos professores.

Apesar dessas formações terem semelhanças com a formação continuada do Programa Norte-rio-grandense de Pensamento Computacional, em relação a organização em módulos, aprendizagem de vários conhecimentos e tecnologias, seleção dos materiais e na organização dos objetivos, elas diferenciam-se na aplicação de algumas estratégias que visam o desenvolvimento profissional dos professores no processo de ensino e aprendizagem em PC. Dessa forma, as experiências evidenciadas anteriormente foram analisadas e contribuíram para a organização e sistematização da proposta do Curso de Formação Continuada de Professores do Programa Norterio-grandense de Pensamento Computacional, que é descrita na próxima seção. 


\section{Programa Norte-rio-grandense de Pensamento Computacional}

O Programa Norte-rio-grandense de Pensamento Computacional (Pensa RN) é uma iniciativa do Programa de Pós-graduação em Inovação em Tecnologias Educacionais (PPgITE) do Instituto Metrópole Digital da Universidade Federal do Rio Grande do Norte. Criado em 2019, o Pensa RN (https://pensarn.imd.ufrn.br/) visa estimular a construção de uma nova cultura de inovação em educação que integre o Pensamento Computacional na dinâmica das ações pedagógicas das Instituições de Ensino Básico do estado do Rio Grande do Norte.

Atualmente, o Pensa RN promove atividades que visam a disseminação do Pensamento Computacional, a utilização de metodologias ativas na educação básica e a formação de professores relacionadas à educação 4.0. Essas atividades promovidas pelo Programa são complementares e visam apoiar as escolas na construção de um ecossistema a partir do contexto local e dos recursos humanos e tecnológicos disponíveis. Para isso, o Pensa RN se organiza em quatro atividades, quais sejam:

- Cursos de formação continuada para professores;

- Clube de programação para alunos do Ensino Fundamental das escolas públicas;

- Sistema de avaliação diagnóstica das habilidades em PC;

- Devolutiva dos resultados da avaliação para as escolas.

Os cursos de formação de professores dispõem de diversos modelos, cargas-horárias e características que os tornam singulares, utilizando diferentes recursos tecnológicos plugados e desplugados, direcionados a docentes interessados em colaborar com a preparação dos alunos nas escolas. Os professores são estimulados em práticas formativas para que possam desenvolver habilidades e ganhar maturidade relacionando a teoria e a prática do Pensamento Computacional através de atividades lúdicas tais como a construção de jogos digitais, atividades gamificadas e práticas de computação desplugada, tornando-se habilitados a promover suas próprias intervenções nas escolas. Esses cursos podem ser de curta duração (10 horas) ou de duração mais longa (60 horas), direcionados a professores com formação em qualquer área de atuação, diferentes níveis de proficiência em tecnologias digitais, metodologias inovadoras e Pensamento Computacional.

A formação de alunos, ocorrida por meio de um clube de programação no Instituto Metrópole Digital, é destinada aos estudantes do $6^{\circ}$ ao $9^{\circ}$ ano das escolas públicas e tem como objetivo desenvolver habilidades para questões relacionadas ao Pensamento Computacional, ao pensamento crítico e criativo, e à resolução de problemas. A proposta do Pensa RN é disseminar as atividades do clube de programação por meio da criação de novos clubes de programação nas próprias escolas, uma vez que os professores responsáveis também recebem a formação necessária para poder liderar um clube na sua própria instituição de ensino.

Considerando o que aponta Valente (2016) sobre a disseminação do Pensamento Computacional nas escolas, tomando como base a ausência de clareza sobre o termo, assim como a formação de professores e avaliação das habilidades desenvolvidas mediante os estímulos ocorridos em práticas educativas, o Pensa RN também objetiva promover avaliação diagnóstica para que as escolas possam ter um melhor conhecimento sobre as habilidades adquiridas pelos seus alunos. Essa avaliação se mostra como uma etapa chave para permitir direcionar as atividades de formação dos alunos, visando estimular as habilidades que eles ainda não adquiriram para que possam desenvolver o seu potencial. Ou seja, objetiva ajudar as escolas a melhor compreenderem as dificuldades dos alunos em relação às habilidades elencadas na $\mathrm{BNCC}$ relacionadas ao PC, assim como revelar os desafios das aprendizagens dos estudantes em relação às competências gerais 2, 4 e 5, referentes ao pensamento científico, crítico e criativo, comunicação e cultura digital. Em relação às devolutivas, a proposta é apresentar os resultados às escolas para que, dessa 
forma, possam ter uma melhor compreensão sobre as fragilidades existentes na aprendizagem dos seus alunos.

A Figura 2 mostra alguns exemplos de cursos que foram ministrados no âmbito do Pensa RN desde a sua criação no segundo semestre de 2019, conforme os detalhes apresentados sobre cada curso no portal do Programa (https://pensarn.imd.ufrn.br/). Destaca-se que esses cursos atenderam a 120 alunos e 270 professores da Educação Básica até o final de 2020, impactando positivamente nas escolas atendidas pelo Programa.

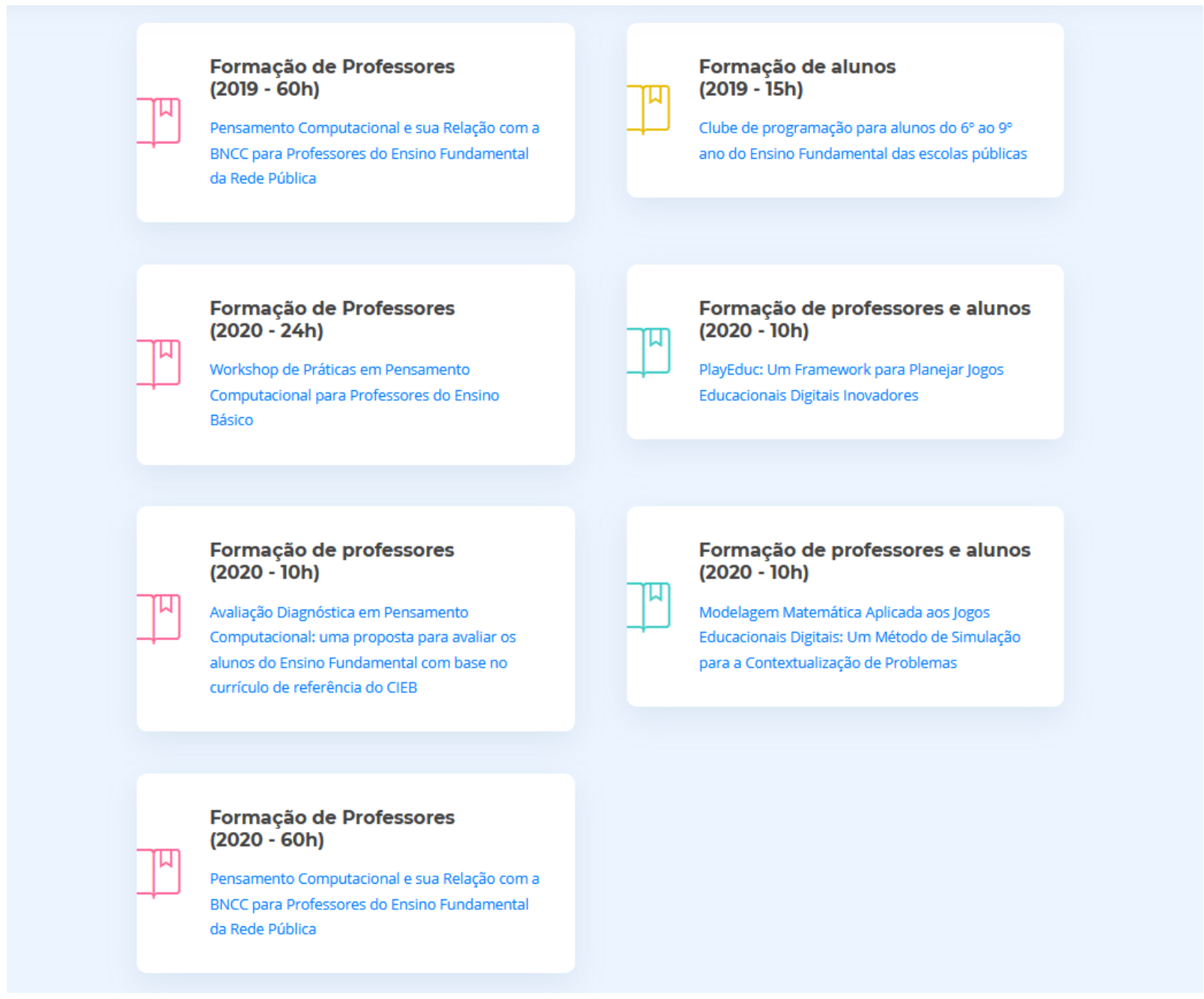

Figura 2: Cursos ofertados no contexto do Programa Norte-rio-grandense de Pensamento Computacional.

Após iniciada a pandemia da Covid-19, as atividades do Pensa RN tiveram que ser adaptadas para o formato online, passando a contar com encontros virtuais síncronos e assíncronos nos cursos de formação ofertados. A única atividade que teve que ser interrompida temporariamente, sofrendo assim grande impacto devido a necessidade de uso do laboratório de informática para a sua realização, foi o clube de programação. Por esta razão, o foco tem sido dado aos cursos de formação de professores.

\section{Proposta do Curso de Formação Continuada de Pensamento Computacional do Pensa RN}

O presente curso de formação continuada de professores em Pensamento Computacional é parte do Programa Norte-rio-grandense de Pensamento Computacional. Além de conhecimentos, 
habilidades e competências docentes, a proposta de formação continuada de professores foi planejada e operacionalizada por uma equipe multidisciplinar, composta por discentes e docentes de cursos de pós-graduação em nível de mestrado e doutorado com formações iniciais nas áreas da Ciência da Computação, Pedagogia e Psicologia. A proposta foi desenhada visando:

- Mobilizar a elaboração de trilhas de aprendizagem para serem aplicadas com os alunos;

- Formular situações de aprendizagem com foco na exploração e utilização de materiais e documentos que fazem parte do desenvolvimento profissional dos docentes, como é o caso da BNCC e do Currículo do CIEB;

- Elaborar materiais desplugados para serem utilizados pelos professores com os alunos.

Os módulos tiveram uma organização didático-pedagógica em que os objetivos geral e específicos de aprendizagem, metodologia, recursos didáticos e referências foram sistematizados em um modelo de trilha previamente definida pela equipe multidisciplinar. No modelo da trilha, os formadores tinham que definir, com base nos objetivos do curso, os objetivos específicos, as estratégias metodológicas, os recursos didáticos e as ferramentas que melhor atendessem aos objetivos de aprendizagem propostos e aos critérios de avaliação dos professores.

Conforme aponta Ramalho (2013), a formação continuada deve mobilizar saberes docentes que provoquem novas aprendizagens capazes de tributar ao desenvolvimento profissional dos educadores, em sua forma de pensar e agir no exercício da sua profissão. Nesse sentido, a formação continuada do Programa Norte-rio-grandense de Pensamento Computacional foi planejada para alcançar objetivos relacionados à aprendizagem da profissão, a formação e o desenvolvimento profissional do professor, com vistas a:

- Promover a formação de profissionais que conduzam a aplicação das tecnologias educacionais de Pensamento Computacional, visando a solução de problemas relacionados ao ensino e à aprendizagem, de forma a atender demandas de naturezas diversas das instituições de ensino;

- Possibilitar a continuidade formativa de docentes atuantes no Ensino Fundamental;

- Construir colaborativamente conhecimentos que possibilitem o desenvolvimento de valores, competências, habilidades e capacidades que promovam um exercício profissional crítico-reflexivo através das tecnologias educacionais;

- Estabelecer relação entre aspectos teóricos e práticos sobre o uso pedagógico das tecnologias digitais;

- Propiciar experiências que contribuam para a inovação das práticas pedagógicas.

Os módulos foram organizados de modo a estimular a mudança de mentalidade dos professores sobre as possibilidades de implementação de práticas pedagógicas integrando o Pensamento Computacional, mesmo em contextos de aprendizagem em que haja extrema escassez tecnológica nos espaços escolares.

Destaca-se que a proposta de formação continuada, descrita e narrada neste artigo, foi embasada em trabalhos anteriores que indicaram estratégias, recursos tecnológicos e materiais didáticos, assim como organização e estrutura dos módulos. Dentre esses, estão os trabalhos de (Valente, 2016; Brennan \& Resnick, 2012; Grover \& Pea, 2013), que contribuíram fortemente na organização dos conteúdos dos módulos e na formulação das trilhas de aprendizagem, além daqueles demais estudos citados na seção de trabalhos relacionados.

A formação continuada foi estruturada inicialmente em dez módulos, totalizando 60 horas de carga horária, contemplando aspectos relacionados à visão sobre as mudanças que a sociedade atual tem passado, o conceito e os pilares do pensamento computacional, além de práticas plugadas e desplugadas. O curso foi organizado conforme descrito no Quadro 1. 
Quadro 1: Módulos e carga horária do curso de formação continuada.

\begin{tabular}{|c|c|c|}
\hline Módulo & Descrição & Carga Horária \\
\hline Módulo 01 & Programa de Inovação Educação Conectada & $6 \mathrm{~h}$ \\
\hline Módulo 02 & Currículo de Referência em Tecnologia e Computação & $6 \mathrm{~h}$ \\
\hline Módulo 03 & Pensamento Computacional & $6 \mathrm{~h}$ \\
\hline Módulo 04 & Olimpíadas de Conhecimento & $6 \mathrm{~h}$ \\
\hline Módulo 05 & Pensa RN & $6 \mathrm{~h}$ \\
\hline Módulo 06 & Prática do Pensamento Computacional com Computação Desplugada & $6 \mathrm{~h}$ \\
\hline Módulo 07 & Prática do Pensamento Computacional com a Hora do Código & $6 \mathrm{~h}$ \\
\hline Módulo 08 & Prática do Pensamento Computacional com Scratch & $6 \mathrm{~h}$ \\
\hline Módulo 09 & Prática de Observação da Execução de Clube de programação & $6 \mathrm{~h}$ \\
\hline Módulo 10 & Prática de Avaliação Diagnóstica das Habilidades do Pensamento & \\
\hline
\end{tabular}

O módulo 1 teve como objetivo discutir com os professores as mudanças observadas e sentidas na sociedade atual, os desafios que os estudantes deverão estar preparados para resolver em razão das transformações e das mudanças provocadas pelos avanços científicos e tecnológicos. Neste módulo ainda foi estimulado a mudança de mentalidade dos professores, conhecendo e vivenciando as dimensões do Programa de Inovação Educação Conectada: visão, competências e formação, recursos educacionais e infraestrutura, por meio da reflexão através da matriz SWOT, seguido por elaboração e criação de um plano de ação.

O módulo 2 objetivou apresentar e explorar o Currículo de Referência em Tecnologia e Computação do CIEB, relacionando-o com o currículo da rede de ensino e a BNCC. Em relação ao currículo do CIEB, os professores foram estimulados a refletir, explorar e identificar os elementos que constituem este documento, além de conhecerem os diversos materiais relacionados às habilidades da BNCC que poderiam ser utilizados pelos professores em suas práticas de ensino.

Os módulos 3 e 4 tiveram o objetivo incentivar a aprendizagem de conceitos relacionados ao pensamento computacional e às olimpíadas de conhecimento. No módulo 3 , o objetivo consistiu em apresentar e trabalhar com os professores a partir da exploração do currículo do CIEB, as dimensões do pensamento computacional (decomposição, abstração, reconhecimento de padrões e algoritmos) para a sua integração na área de conhecimento dos professores. No módulo 4, o objetivo consistiu em apresentar as olimpíadas de conhecimento, especialmente a Olimpíada Brasileira de Informática, para promover a compreensão dos professores sobre a importância destas olimpíadas na formação dos estudantes.

No módulo 5 foi apresentado o Programa do qual o presente curso de formação continuada faz parte. Este módulo foi inserido neste momento em razão da organização do curso entender que seria mais fácil conseguir adesão dos professores na implementação da proposta central do Pensa RN assim que estes tivessem sido sensibilizados quanto às mudanças pelas quais passam a sociedade contemporânea, assim como conhecessem o conceito de pensamento computacional e tivessem a oportunidade de integrá-lo na sua prática de ensino. Dessa forma, o módulo apresentou 
o Pensa RN em detalhes, sua importância e principais ações junto aos professores e estudantes da educação básica.

Nos módulos 6, 7 e 8 os professores tiveram a oportunidade de experimentar a construção de conceitos e saberes sobre computação desplugada e computação plugada mediante atividades práticas utilizando gamificação, jogos, Scratch e os desafios da Hora do Código. Estes módulos tiveram como objetivo principal apresentar recursos educacionais digitais que os professores pudessem utilizar para desenvolver práticas de ensino integradas ao PC.

No módulo 9, os professores frequentaram o clube de programação do Pensa RN com o intuito de adquirir uma primeira experiência com a aplicação de atividades plugadas juntamente aos alunos dos anos finais do Ensino Fundamental. Enfim, no módulo 10 estava prevista a aplicação de um modelo de avaliação diagnóstica para as habilidades do PC. Porém, por questões de organização e adaptações em razão de mudanças de agendas, feriados e outros desafios, esse último módulo não pôde ser realizado como o previsto. Portanto, os professores foram incentivados a dar continuidade com a participação nos encontros do clube de programação.

Quanto à metodologia do curso, durante os módulos foram utilizadas estratégias baseadas na resolução de problemas, computação desplugada, jogos digitais e programação visual a fim de estimular os professores para o desenvolvimento do pensamento computacional de uma forma prática e colaborativa.

Em relação a avaliação dos professores, esta ocorreu de forma processual e formativa utilizando-se de diversos materiais e produções dos professores durante o curso de formação continuada como, por exemplo, trilhas de aprendizagem, participação ativa nos módulos, criação de artefatos de jogos ou animações nos ambientes de programação visual e observação subjetiva dos formadores ministrantes do curso. Ademais, para receberem o certificado de participação, os docentes deveriam ter pelo menos $75 \%$ de presença em todo o curso.

Em relação à avaliação da qualidade do curso, foram aplicados questionários durante e após os módulos, assim como no final do curso. Para coleta dos dados de avaliação, foram utilizados dois tipos de formulários online estruturados para produzir o perfil do formador, o perfil docente dos participantes e a avaliação do curso.

\section{Aplicação da proposta de Formação Continuada do Programa Norte-rio- grandense de Pensamento Computacional}

O curso de formação continuada do Pensa RN ocorreu no período de setembro a novembro de 2019, contando com 40 professores do ensino fundamental da rede estadual de ensino do Rio Grande do Norte, com faixa etária de 27 a 57 anos e média de idade de 42 anos, sendo 55,6\% do sexo feminino e 44,6\% do sexo masculino. Quanto ao tempo de docência, os professores mais novos tinham de 3 a 6 anos de atuação, enquanto que os mais experientes chegavam a 34 anos de profissão. A maior parte dos professores tinham tempo de profissão superior a 15 anos.

No módulo um, em um primeiro momento foi utilizada a dinâmica do World Café, um processo colaborativo que visa trabalhar a diversidade e complexidade no grupo, fazendo emergir a inteligência coletiva (Lévy, 2007). Os participantes se organizaram em grupos e refletiram sobre as forças, oportunidades, fraquezas e ameaças (Matriz SWOT) acerca das dimensões visão, competências e formação, recursos educacionais e infraestrutura do Programa de Inovação Educação Conectada (PIEC).

No segundo momento houve a utilização da ferramenta para planejamento estratégico $5 \mathrm{~W} 2 \mathrm{H}$, com vistas a estimular nos professores uma nova perspectiva acerca da realidade de suas escolas. Organizados em grupos, os professores se reportaram às reflexões levantadas no World 
Café para construir e propor soluções frente às dimensões do PIEC, desenvolvendo práticas inovadoras que fossem possíveis de aplicação em suas respectivas escolas. Inicialmente, os professores tiveram dúvidas sobre como poderiam propor soluções para os problemas enfrentados em suas respectivas escolas, alegando que a grande maioria dos problemas enfrentados estava relacionado com a infraestrutura, devido aos recursos escassos disponíveis nas escolas. Para a surpresa de todos, embora fossem de escolas distintas, muitos dos problemas eram semelhantes, o que possibilitou aos professores a concepção de soluções que poderiam ser aplicadas em qualquer uma das escolas representadas. Na Figura 3 é possível observar dois grupos de professores apresentando seus projetos.

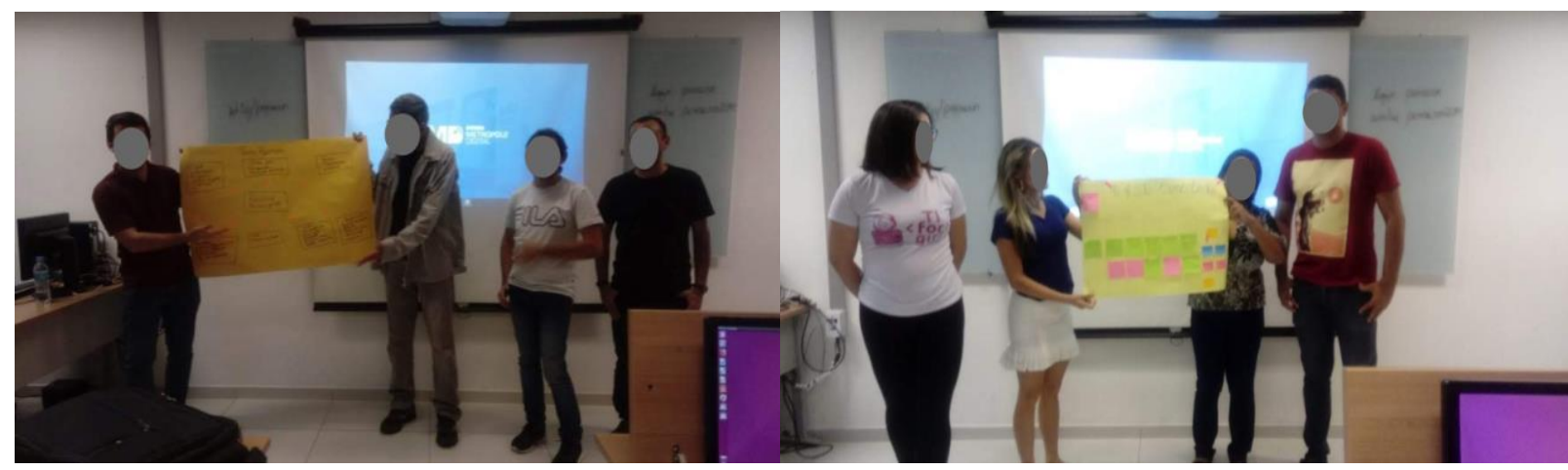

Figura 3: Professores apresentando os projetos desenvolvidos no módulo 1 utilizando a metodologia 5W2H e World Café.

Destaca-se, no entanto, que quase todos os grupos de professores tiveram foco em soluções que não dependiam exatamente deles, como por exemplo a compra de equipamentos de informática, a melhoria na administração e gestão dos recursos da escola, a oferta de formações continuadas na própria escola, a promoção de eventos para arrecadação de fundos, etc. Foram poucos os professores que apontaram para a necessidade de uma nova ecologia na escola, em que eles pudessem ser protagonistas juntamente com os estudantes por meio de atividades e ações colaborativas e inovadoras, trabalhando com metodologias ativas e com os recursos disponíveis dentro e fora da escola, independentemente da utilização de tecnologias digitais.

Essa observação foi extremamente valiosa para que nos módulos seguintes fossem reforçadas as situações de aprendizagem colaborativa, estimulando os professores para refletirem sobre o que, como, para quê, e, porquê utilizar as tecnologias disponíveis na escola para a integração do Pensamento Computacional em sua prática de ensino.

No módulo 2, os professores tiveram que selecionar e analisar um plano de aula do portal do Programaê (http://programae.org.br/) para compreender como os planos de aulas foram criados e como poderiam ser aplicados em suas realidades de ensino. A proposta do módulo era apresentar aos professores os materiais e os recursos disponíveis que poderiam ser aplicados com seus alunos. Após essa exploração dos materiais, os professores analisaram um plano de aula voltado ao ensino da educação física para os estudantes do $7^{\circ}$ ano do Ensino Fundamental.

Neste módulo ficou evidente que muitos professores não apresentavam muita familiaridade com os recursos tecnológicos digitais. Além dessa constatação ser um dado bastante significativo, que pode influenciar a permanência ou não dos professores no curso, este dado também aponta para os desafios que o Brasil ainda terá que avançar para integrar as tecnologias digitais de forma inovadora, como recursos de criação, colaboração e transformação social. Além das dificuldades em localizar o portal do Programaê e navegar nele, os professores também tiveram dificuldades em compreender o objetivo da atividade proposta, demonstrando assim a necessidade de ter que trabalhar o básico do uso dos sistemas computacionais.

No módulo 3, o objetivo era contribuir com a formação dos professores no sentido de estimular a compreensão sobre o que é o pensamento computacional, sua relação com a educação 
e como poderia ser integrado à prática de ensino das diversas áreas de conhecimento. Para alcançar esses objetivos, no módulo foram utilizadas as seguintes estratégias didáticas nos encontros: apresentação dialogada de slides sobre a contextualização do módulo e teoria do pensamento computacional; discussão colaborativa sobre o tema do encontro de formação; e o direcionamento sobre a trilha integrando o pensamento computacional à prática de ensino dos professores.

Para além, foram propostos momentos de vivências colaborativas, envolvendo atividades utilizando programação plugada e desplugada, por meio de atividades como cupcakes e estacionamento do site (https://www.computacional.com.br/) e os jogos Compute-it (http://compute-it.toxicode.fr/) e Lightbot (https://ightbot.com/) que possibilitaram trabalhar os pilares do pensamento computacional.

Quanto à experimentação da computação plugada, esta ocorreu de forma individual no laboratório de informática e foi direcionada com base em diversas questões, tais como: "Você consegue aplicar as dimensões do pensamento computacional?"; "Em qual(is) situação(ões) você aplicou a abstração, a decomposição, o reconhecimento de padrões e a elaboração de algoritmo no jogo?".

Em relação à vivência utilizando a computação desplugada, os professores foram organizados em quatro grupos compostos por cinco ou seis membros. As atividades desplugadas foram organizadas em quatro estações em que os professores passavam de atividade em atividade, trocando-as em intervalos de 30 a 40 minutos. A Figura 4 apresenta alguns registros da aplicação das dinâmicas com os professores.

Quanto à avaliação dos professores, para além dela ocorrer de forma processual e formativa, também foi solicitado aos professores a elaboração e aplicação de uma prática pedagógica integrada ao Pensamento Computacional. Em relação a avaliação do módulo, foi realizada aplicação de um formulário online para validar as metodologias, estratégias, recursos utilizados e a linguagem adotada pelos formadores durante os encontros.

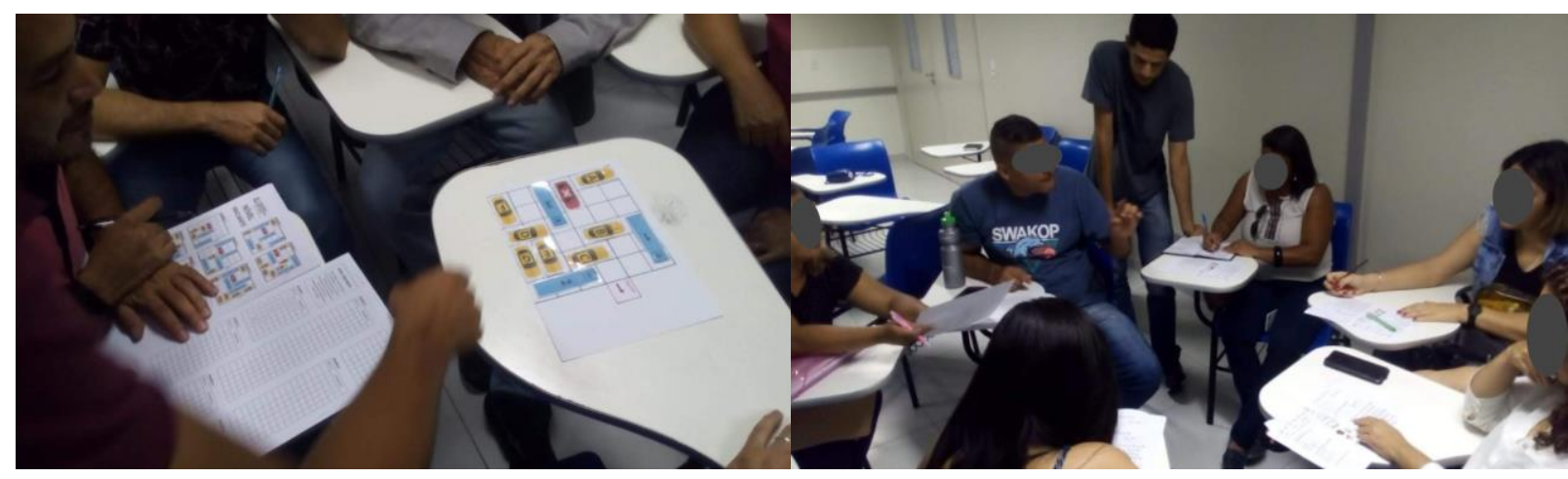

Figura 4: Professores resolvendo atividades de computação desplugada.

A avaliação dos encontros formativos não foi obrigatória. Portanto, apenas 16 professores avaliaram o módulo. Para os professores, o tempo dedicado ao módulo, a metodologia empregada, os recursos utilizados, o domínio apresentado pelos formadores e a clareza na comunicação se mostraram de acordo com as suas expectativas, ficando com variações entre quatro e cinco pontos, considerando uma escala de um a cinco.

Em relação à produção dos planos de aula integrando o Pensamento Computacional, todos os professores produziram trilhas de aprendizagem, em alguns casos de forma colaborativa. As trilhas foram aplicadas posteriormente com os estudantes de várias escolas da rede estadual de ensino. Destaca-se que essas propostas de ação pedagógica serão disponibilizadas para consulta no portal do Pensa RN. 
No módulo 4, os formadores apresentaram os benefícios para os alunos, professores e escolas em participar das olimpíadas brasileiras de conhecimento, inclusive para ajudar a identificar possíveis casos de estudantes com altas habilidades. Após a aplicação inicial dos conceitos durante a apresentação dialogada sobre os temas do encontro, os professores foram organizados em grupos de seis membros. Em seguida, foram sorteadas as olimpíadas para que cada grupo pudesse se aprofundar e trazer informações para o grande grupo. Os professores deveriam elaborar uma apresentação sobre o tema do encontro e, depois, apresentar os seus achados para a turma.

Por meio dos slides criados pelos professores foi possível perceber que estes conseguiram entender como esses eventos são organizados, quais recursos são necessários e utilizados nas olimpíadas e, principalmente, sobre a importância desses eventos educacionais para descobrir novos talentos.

No módulo 5 ocorreu a apresentação do Programa Norte-rio-grandense de Pensamento Computacional, indicando sua importância, suas principais ações e explicação de como a avaliação diagnóstica está sendo construída. O módulo ocorreu de forma teórica, utilizando-se basicamente de apresentação dialogada sobre o tema, não havendo nenhuma produção concreta para ser elaborada pelos professores uma vez que o objetivo era a sensibilização. Entretanto, esta ação foi importante para que os professores tivessem clareza sobre a dimensão do trabalho proposto, visando colaborar para a construção de um ecossistema de inovação e mudanças em suas práticas docentes, impactando assim na vida dos estudantes envolvidos nos clubes de programação em suas escolas.

No módulo 6, de Pensamento Computacional com computação desplugada, o objetivo consistiu em estimular vivências práticas dos professores na aplicação de recursos utilizando o Pensamento Computacional, mesmo em situações de extrema escassez tecnológica digital. No módulo, foram utilizadas as seguintes estratégias: apresentação dialogada sobre o tema, dinâmica gamificada e aplicação de um jogo da "caça pensamento computacional" (https://www.encurtador.com.br/oquDZ), conforme apresentado na Figura 5.

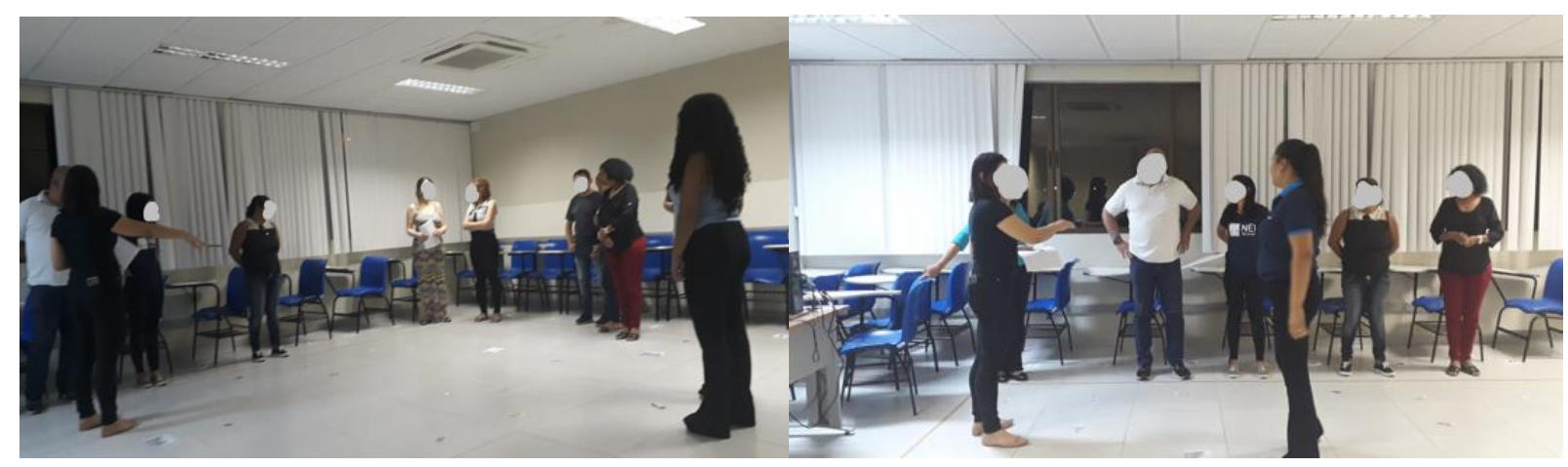

Figura 5: Aplicação do jogo "caça pensamento computacional”, envolvendo conhecimento da Matemática Financeira.

Neste módulo não foi solicitado aos professores nenhum planejamento com Pensamento Computacional desplugado. Entretanto, após este módulo, muitos professores compartilharam registros de aplicações de atividades de computação desplugada realizadas em suas escolas, semelhantes às apresentadas neste módulo e no módulo de Pensamento Computacional, conforme pode ser observado na Figura 6. Essa disposição deles em aplicar o Pensamento Computacional sem solicitação explícita dos formadores sugere que a formação serviu para incentivá-los, mostrando-os como desenvolver práticas educativas integradas ao Pensamento Computacional. 


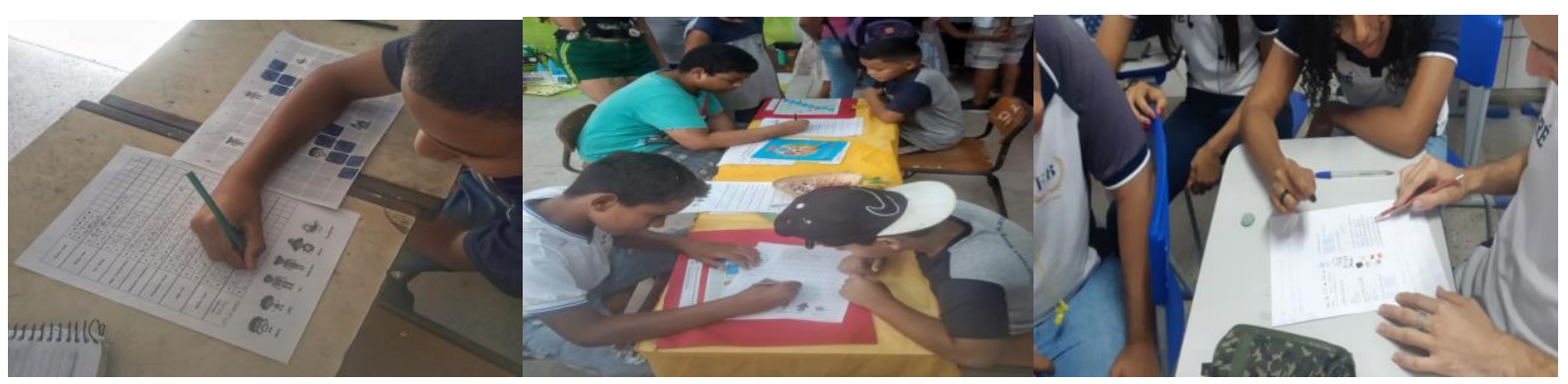

Figura 6: Atividade de computação desplugada sendo realizada por alunos de escolas públicas da rede estadual de ensino.

Nos módulos 7 e 8, aos professores foram apresentados os recursos para desenvolvimento e aplicação de propostas utilizando a criação de narrativas e animações. Nestes módulos, os professores tiveram a oportunidade de navegar nas plataformas da Hora do Código e do Scratch, exercitando a programação, observando os jogos existentes e planejando um jogo para ser desenvolvido posteriormente. A Figura 7 apresenta registros dos encontros.

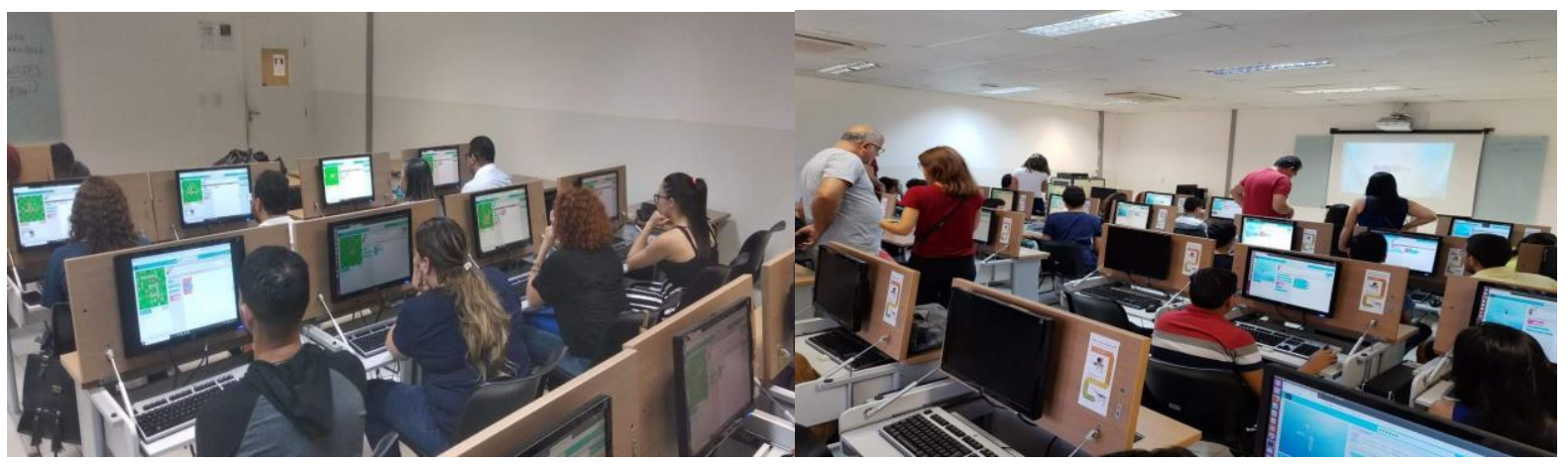

Figura 7: Práticas utilizando as plataformas da Hora do Código e do Scratch no laboratório de Informática.

Assim como no módulo de computação desplugada, os formadores envolvidos não solicitaram nenhuma atividade de planejamento e aplicação de propostas envolvendo o novo conhecimento adquirido pelos professores. Todavia, mesmo sem ter sido uma solicitação do módulo, os professores não deixaram de aplicar a computação plugada com os alunos. A Figura 8 apresenta evidências da aplicação desse novo conhecimento na prática educativa dos docentes nas escolas, conforme também pode ser atestado em vídeo disponibilizado no canal do YouTube do Pensa RN (https://www.youtube.com/watch?v=TDRNDYyrk5k).

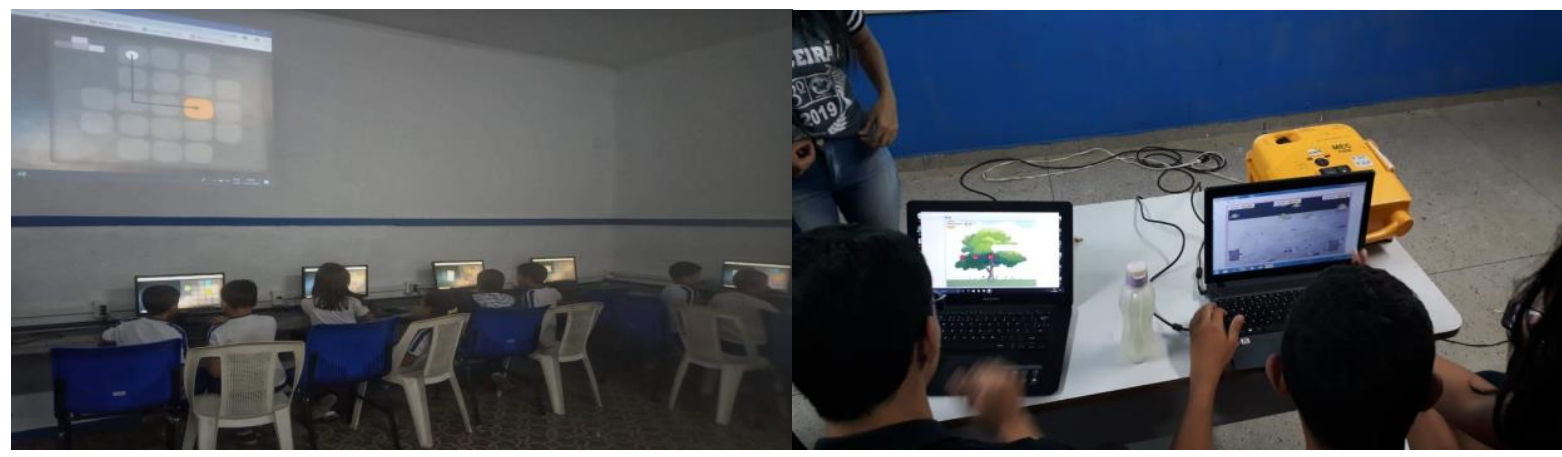

Figura 8: Práticas utilizando as plataformas da Hora do Código e do Scratch com os estudantes da rede estadual de ensino.

Nos módulos 9 e 10, os professores foram convidados a participar das intervenções do clube de programação do Programa Norte-rio-grandense de Pensamento Computacional, que estava sendo realizado no mesmo período com 120 alunos dos anos finais do Ensino Fundamental das escolas públicas, divididos em 3 turmas de 40. Os professores experienciaram a aplicação de diversas atividades de programação com várias ferramentas, compreendendo assim como um 
clube funciona e qual é o trabalho de mediação que precisa ser efetuado juntamente com os alunos. Um dos interesses principais desta participação dos professores no clube foi incentivá-los a criar clubes de programação nos seus próprios ambientes de trabalho a fim de dar a oportunidade para os alunos das respectivas escolas.

\section{Avaliação do Curso de Formação}

A avaliação do curso ocorreu mediante a aplicação de um formulário elaborado com questões abertas e fechadas, conforme indicado por Gil (2008), quais sejam: (a) avaliação da estrutura do curso; (b) impacto do curso na formação dos professores; (c) aplicação do Pensamento Computacional nas escolas; e (d) avaliação subjetiva da formação. A avaliação foi respondida por 18 professores dos 40 que fizeram o curso de formação, sendo 8 formados em Pedagogia, $3 \mathrm{em}$ Geografia, 1 em História, 4 em Matemática e 2 em Língua Portuguesa.

\subsection{Avaliação da Estrutura do Curso}

Questionados sobre o quanto o curso de extensão em Pensamento Computacional atendeu às suas necessidades formativas em diferentes aspectos, os professores indicaram um alto nível de satisfação, uma vez que o curso mobilizou a construção de novas experiências de aprendizagem.

Para 13 participantes do curso, a carga horária dos módulos foi considerada satisfatória para realização das atividades. Em relação ao formato presencial, 10 professores indicaram que a experiência foi muito satisfatória, 2 indicaram como sendo satisfatória, 1 indiferente, 1 insatisfatório e 4 muito insatisfatório. Essa insatisfação apresentada por 5 professores indicou que eles preferiam experiências formativas online ou híbridas, em razão do cansaço do deslocamento até o campus central da UFRN em razão de morarem em municípios do interior do Estado.

A organização dos módulos apresentados pela formação foi considerada muito satisfatória para 9 professores, satisfatória para 3, indiferente para 1 e muito insatisfatório para 4 professores. Esse dado revela a necessidade de melhoria na organização dos módulos, podendo ocorrer a renovação ou a reorganização deles de forma que possam dialogar entre si. Além disso, o número elevado de insatisfação pode sugerir também que não houve contextualização e diálogo entre os módulos a ponto dos professores perceberem as relações que existiam entre eles.

Quanto aos materiais, recursos e as metodologias utilizadas na formação, 14 professores indicaram que estavam pelo menos satisfeitos e 4 indicaram insatisfação com os materiais, recursos e as metodologias utilizadas pelos formadores durante a aplicação dos módulos. Saber que os materiais, recursos e as estratégias metodológicas utilizados foram bastante satisfatórios para os professores é importante para podermos continuar no processo de melhoria contínua, selecionando e elaborando os materiais a serem utilizados nas formações do Pensa RN. Além disso, ao avaliar os materiais, recursos e as metodologias utilizadas pelos formadores, os professores apontaram que a formação contribuiu para o estímulo e desenvolvimento de habilidades do conhecimento pedagógico do conteúdo e conhecimento pedagógico tecnológico, uma vez que conseguiram perceber relevância nos materiais e nas estratégias e recursos utilizados relacionados ao ensino do Pensamento Computacional, que podem ser replicados posteriormente pelos professores em suas próprias escolas.

A atuação dos formadores do curso também foi avaliada pelos professores participantes do curso, com 14 deles indicando satisfação com a qualidade das atividades desenvolvidas e a forma de mediação da equipe de formação. 


\subsection{Impacto do Curso na Formação dos Professores}

Em relação ao impacto do curso na formação dos participantes, $100 \%$ dos docentes indicaram que o curso possibilitou adquirir um bom conhecimento sobre o Pensamento Computacional, sendo que $61,1 \%$ indicaram que a experiência foi mais que satisfatória para a aprendizagem do tema. Essa análise dos professores sobre a aprendizagem do Pensamento Computacional está fortemente relacionada com o impacto que a formação conseguiu gerar para eles, estimulando-os na aquisição do conhecimento e colocando-os para vivenciar situações práticas que permitiram adquirir habilidades essenciais sobre o tema.

Sobre a confiança para aplicar o Pensamento Computacional em suas práticas de ensino, $94,4 \%$ dos docentes indicaram que a formação proporcionou o surgimento da confiança necessária para desenvolver atividades envolvendo o PC nas escolas.

Em relação aos conhecimentos pedagógicos do conteúdo e tecnológicos do conteúdo, $88,9 \%$ dos docentes afirmaram que a formação contribuiu satisfatoriamente para que pudessem criar materiais didáticos e atividades adaptadas ao tema para aplicação em sala de aula.

\subsection{Aplicação do Pensamento Computacional nas Escolas da Rede}

Quanto à transposição do conhecimento adquirido na formação para as escolas dos professores, $88,9 \%$ dos professores indicaram que aplicaram o Pensamento Computacional em suas práticas de ensino e aprendizagem. 16 professores desenvolveram atividades envolvendo o tema com seus alunos ainda durante o curso. Esses professores indicaram que utilizaram, principalmente, atividades desplugadas, conforme apresentado na Figura 9.

16 respostas

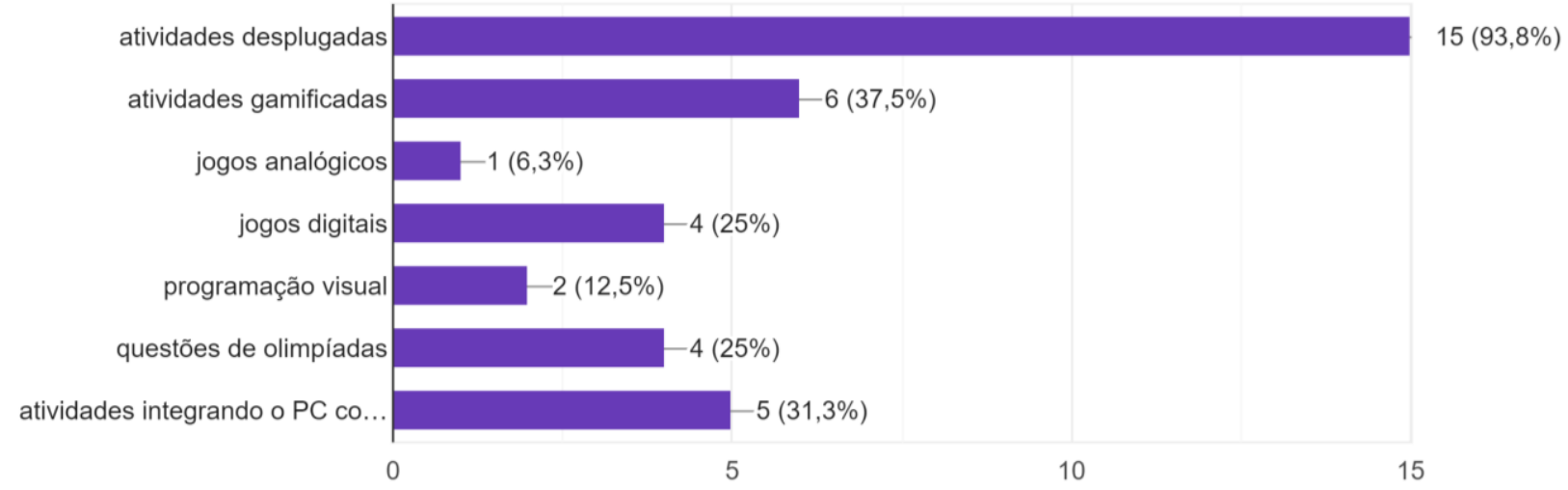

Figura 9: Atividades aplicadas com os estudantes das escolas públicas da rede durante o curso de formação.

Questionados sobre a aplicação das atividades envolvendo o Pensamento Computacional nas suas respectivas áreas de conhecimento, juntamente com os estudantes após a finalização do curso, os resultados são semelhantes àqueles apresentados na Figura 9.

Os dois docentes que não aplicaram o Pensamento Computacional em suas práticas de ensino com os estudantes alegaram motivos distintos. Um dos docentes informou que estava no cargo de gestor escolar e, portanto, não teria turma para realizar a aplicação. $\mathrm{O}$ outro docente informou que ainda não se sentia seguro o suficiente para desenvolver práticas de PC em suas ações pedagógicas. Apesar de não terem feito aplicação do PC com seus alunos, ambos docentes indicaram interesse em desenvolver atividades futuras sobre o tema nas suas práticas. 


\subsection{Avaliação Subjetiva da Experiência Formativa na Perspectiva dos Participantes}

No que se refere à avaliação subjetiva do curso, realizada pelos professores participantes, no Quadro 2 é possível observar as questões elaboradas e inseridas no formulário de avaliação, bem como o resultado da aplicação.

A partir da análise subjetiva da avaliação é possível identificar que o curso atendeu às expectativas dos professores quanto aos aspectos relacionados à qualificação técnica dos formadores, a qualidade dos materiais e recursos empregados, metodologias adotadas e as atividades envolvendo os participantes. Isto indica que estes elementos do design de aprendizagem do curso se mostraram válidos e esses recursos e materiais poderão ser reutilizados posteriormente.

Em relação aos aspectos em que os professores consideraram pontos a serem melhorados, ficou claro que o modelo presencial do curso não atendeu em plenitude às demandas dos professores, visto que muitos participantes relataram que era cansativo, principalmente para quem era do interior do Estado. Segundo os professores, o cansaço era fruto de um dia inteiro de trabalho em mais de uma escola. Ademais, os professores passavam o dia inteiro ministrando aulas e ainda tinham que se deslocar duas vezes por semana até o curso, que tinha duração de três horas de aulas-relógio.

Esse modelo de ensino, em que a presença física era necessária para execução do curso e desenvolvimento das atividades planejadas, além de ser visto pelos professores como algo negativo, pode ter sido também uma das causas de evasão no curso. Outro aspecto bastante significativo que também influenciou negativamente na permanência de alguns professores no curso foi o fato deles terem pouca proficiência tecnológica, desistindo do curso tão logo começaram as atividades plugadas no laboratório de informática.

Quadro 2: Avaliação subjetiva dos professores sobre o curso de formação continuada.

\begin{tabular}{|l|l|}
\hline $\begin{array}{l}\text { O que foi } \\
\text { bom? }\end{array}$ & $\begin{array}{l}\text { Possibilidade de conhecer o pensamento computacional e aprender mecanismos para melhorar a } \\
\text { prática educativa; didática e recursos utilizados no curso; interação e colaboração com outros } \\
\text { colegas; qualificação técnica dos formadores; aprendizado quanto ao uso de novas ferramentas } \\
\text { digitais; vivências e realização de atividades com ênfase nas habilidades e competências da } \\
\text { BNCC; curso ter sido presencial; aplicabilidade do tema no contexto escolar. }\end{array}$ \\
\hline $\begin{array}{l}\text { O que não foi } \\
\text { bom? }\end{array}$ & $\begin{array}{l}\text { Curso ter sido de curta duração; cortes de energia no local do curso; carga horária cansativa dos } \\
\text { encontros semanais; horário avançado de término das aulas e deslocamento dos professores para } \\
\text { suas respectivas residências; curso em formato totalmente presencial; falta de objetividade na } \\
\text { apresentação de algumas atividades; módulo das olimpíadas cansativo; distância de casa e } \\
\text { cansaço após dia de trabalho; encontros aos sábados no clube de programação. }\end{array}$ \\
\hline $\begin{array}{l}\text { Quais } \\
\text { melhorias } \\
\text { você sugere } \\
\text { para o curso? }\end{array}$ & $\begin{array}{l}\text { Ampliar a carga horária do curso; desenvolver mais atividades práticas; aumentar a duração de } \\
\text { alguns módulos, como o de olimpíadas e de computação desplugada; propor novos módulos para } \\
\text { a continuidade do curso; evoluir o curso para transformá-lo em curso de especialização; refletir } \\
\text { sobre a acessibilidade no desenvolvimento das atividades; disponibilizar mais tempo para os } \\
\text { momentos de planejamento das atividades e aplicação das mesmas em sala de aula; adotar o } \\
\text { formato semipresencial para propor atividades a distância; elaborar materiais teóricos para } \\
\text { estudo; disponibilizar materiais em AVA; explorar a aprendizagem baseada em projetos. }\end{array}$ \\
\hline
\end{tabular}

Quanto às melhorias do curso, os professores indicaram basicamente uma necessidade de aumento da carga horária de atividades práticas, principalmente envolvendo computação desplugada e exercícios das olimpíadas de informática; atividades inclusivas para estudantes; adoção do modelo semipresencial; além de elaboração de materiais de apoio. 
Portanto, os resultados da formação continuada de professores do Programa Norte-riograndense de Pensamento Computacional parecem estar caminhando adequadamente, visto que as experiências desenvolvidas pelos professores no ambiente do curso demonstraram que apenas dois professores não se motivaram a aplicar o Pensamento Computacional em suas turmas.

\section{Resultados e discussões}

Em relação aos resultados gerais do curso, 22 professores chegaram a concluir a formação continuada. Dentre aqueles que finalizaram, 18 responderam ao formulário de avaliação. Dentre aqueles que responderam ao formulário, 16 afirmaram que aplicaram o pensamento computacional com seus alunos nas escolas. No que se refere aos professores que desenvolveram práticas educativas envolvendo o pensamento computacional em suas práticas de ensino, 15 indicaram que fizeram uso de atividades desplugadas, 6 afirmaram utilizar atividades gamificadas e 5 apontaram que realizaram atividades integrando o PC na sua área de conhecimento.

Apenas 6 professores fizeram uso de computação plugada em suas escolas, reforçando a importância da computação desplugada como uma estratégia fundamental para disseminação do Pensamento Computacional, sobretudo naquelas escolas que contam com pouca infraestrutura tecnológica. Isto indica também que ainda há muitos desafios a serem superados para que o ensino plugado ocorra, seja com a criação de narrativas e histórias, seja com a construção de animações digitais.

Entretanto, isso também pode revelar uma possível incompreensão dos docentes sobre a utilização das tecnologias digitais. A visão instrucionista ainda é muito presente na educação com o uso das tecnologias digitais, na qual a relação computador-estudante é de um-para-um, em que este ensina aquele.

Todavia, embora a abordagem instrucionista tenha se ofuscado por uma perspectiva de ensino construcionista, ainda há professores que acreditam e defendem que apenas será possível trabalhar com computação plugada nas escolas quando todos tiverem conectados a um computador, esquecendo-se muitas vezes do uso dos smartphones dos estudantes e do ensino híbrido.

É possível que o contexto das escolas públicas da rede, no que se refere à infraestrutura, seja um fator predominante para a adoção da computação desplugada em detrimento da plugada. Mas há também, por parte dos professores, pouca adesão a atividades pedagógicas apoiadas por abordagens híbridas, em que se possa realizar atividades dentro e fora da sala de aula utilizando os smartphones dos estudantes e os computadores disponíveis na escola.

\section{Considerações Finais}

O objetivo deste artigo foi apresentar, descrever e discutir a proposta inicial da formação continuada de professores em Pensamento Computacional do Pensa RN, aplicada com educadores da Educação Básica. Algumas restrições não foram antecipadas e ficaram evidentes no decorrer do curso. Entre elas estão o nível de proficiência tecnológica, o horário, o formato presencial do curso e as diferentes condições encontradas pelos professores nas escolas.

Quanto ao nível de apropriação tecnológica dos professores durante os encontros no laboratório de informática, em que foi necessário utilizar computadores, alguns demonstraram dificuldades com ferramentas básicas, certas vezes até para seguir orientações simples tais como ligar, acessar a rede com uma conta e navegar na internet. 
Outra restrição que se destaca, refere-se às condições de infraestrutura tecnológicas dos professores e estudantes nas escolas públicas, que ainda possuem maturidade tecnológica em níveis básicos, sendo exigido dos professores mais criatividade, habilidades e competências para implantação de projetos educacionais envolvendo alguma tecnologia digital no processo de ensino e aprendizagem.

Além dessas limitações identificadas, aponta-se a fragmentação no número de módulos do curso, a descontinuidade e clareza dos objetivos de cada módulo e da metodologia de transposição didática, assim como a ausência de produto final do curso a ser construído pelos docentes. Alguns encaminhamentos de soluções possíveis para essas restrições identificadas são os seguintes:

- Aplicação de questionário de mapeamento da proficiência tecnológica dos professores, que pode, por exemplo, ser feito por meio do guia EduTec do CIEB;

- Alteração do modelo presencial para uma proposta de formação online ou híbrida, em que ocorra encontros online e, se possível, presenciais, sendo este último utilizado para atividades práticas;

- Alteração do horário da formação adaptada à realidade e disponibilidade dos docentes, com encontros presenciais com duração limitada a 2 horas;

- Redução do número de módulos, adequando-os às necessidades evidenciadas pelos professores da rede ensino;

- Construção de diretrizes claras para formação do Pensa RN, em que todos os formadores saibam que caminho devem perseguir, quais objetivos se deseja alcançar em cada módulo e quais estratégias podem ser utilizadas quando forem construir os planos dos módulos dos cursos.

Com base nos resultados da formação continuada e nas análises dos formadores, assim como pela imposição da pandemia da Covid-19 que abriu um grande espaço para as formações online, a proposta de formação de professores foi revista com perspectivas de avançar para um modelo online, com encontros síncronos e assíncronos. Além disso, migrou para uma organização com base no desenvolvimento de competências docentes, tendo como base o Currículo de Referência em Tecnologia e Computação do CIEB e as Competências Docentes de Pensamento Computacional da Sociedade Internacional para Tecnologia na Educação (ISTE).

Essas mudanças mostram-se necessárias porque a proposta de formação continuada presencial, embora seja interessante para experiências práticas colaborativas, não favorece a capilarização da proposta, assim como evidencia uma evolução no modelo de formação continuada do curso, tendo sido uma das sugestões dos professores.

A formação continuada revelou que os professores, independentemente de área de atuação, sentem necessidade e estão motivados a aplicar e desenvolver projetos integrando o Pensamento Computacional em suas práticas pedagógicas. Porém, precisam de apoio em suas unidades de ensino. Certamente, o que ainda precisa avançar também é a organização do processo e da gestão dos projetos nas escolas, visto que muitos professores revelaram que muitas ações não se concretizam no "chão da escola" por falta de acompanhamento e gerenciamento da equipe gestora.

Isto indica a necessidade de também oferecer formação continuada para coordenadores pedagógicos e gestores no sentido de organizar projetos pedagógicos e espaços incluindo temas como o Pensamento Computacional, aprendizagem criativa e cultura maker nas escolas. 


\section{Agradecimentos}

Este artigo é resultado de uma ação de formação de professores no âmbito do Programa Norterio-grandense de Pensamento Computacional (Pensa RN), na qual diversos discentes do curso de mestrado profissional do Programa de Pós-graduação em Inovação em Tecnologias Educacionais (PPgITE) da Universidade Federal do Rio Grande do Norte (UFRN) estiveram envolvidos na condição de formadores. Por esta razão, agradecemos o empenho, a dedicação e a colaboração de todos os formadores que contribuíram com esta atividade do Pensa RN.

\section{Artigo Premiado Estendido}

Esta publicação é uma versão estendida do artigo premiado no Simpósio Brasileiro de Educação em Computação (EduComp 2021), intitulado "Formação Continuada de Professores em Pensamento Computacional: Um Relato de Experiência do Programa Norte-rio-grandense de Pensamento Computacional”, DOI: 10.5753/educomp.2021.14488.

\section{Referências}

Almeida, M. D., \& Valente, J. A. (2011). Tecnologias e currículo: trajetórias convergentes ou divergentes. São Paulo: Paulus, 1, 93.

Almeida, M. E. B., \& Valente, J. A. (2012). Integração do Currículo e Tecnologias e a Produção De Narrativas Digitais. Currículo Sem Fronteiras, 12(3), 57-82. [GS Search]

Almeida, M. E. B. (2020). Conferência On-line sobre a Formação de professores para a era da informação e das tecnologias digitais. Disponível em: https://youtu.be/1TqfVDAOGKA. Acesso em: 26/06/2021.

Avila, C., B., A., Marques, M., Cavalheiro, S., \& Foss, L. (2016). Desdobramentos do Pensamento Computacional no Brasil. Anais do Simpósio Brasileiro de Informática na Educação (SBIE2016), 27(1), 200-209. doi: 10.5753/cbie.sbie.2016.200 [GS Search]

Barcelos, T., Bortoletto, R., \& Andrioli, M. (2016). Formação online para o desenvolvimento do Pensamento Computacional em professores de Matemática. Anais dos Workshops do Congresso Brasileiro de Informática na Educação, (5)1, 1228-1237. doi: 10.5753/cbie.wcbie.2016.1228 [GS Search]

Blikstein, P. (2008). O pensamento computacional e a reinvenção do computador na educação. Education \& Courses. Disponível em: http://www.blikstein.com/paulo/documents/online/ol_pensamento_computacional.html [GS Search]

Brennan, K., \& Resnick, M. (2012). New frameworks for studying and assessing the development of computational thinking. Proceedings of the 2012 annual meeting of the American educational research association, 1-25. [GS Search]

CGI. (2018). Pesquisa sobre o uso das tecnologias de informação e comunicação nas escolas brasileiras: TIC educação 2018. Comitê Gestor da Internet no Brasil. Disponível em: https://cetic.br/noticia/tic-educacao-2018-cresce-interesse-dos-professores-sobre-o-uso-dastecnologias-em-atividades-educacionais/.

Cavalcante, A., Costa, L. S., \& Araújo, A. L. (2016). Um estudo de caso sobre competências do pensamento computacional desenvolvidas na programação em blocos no Code.Org. Anais 
dos Workshops do Congresso Brasileiro de Informática na Educação, 5(1), 1117-1126. doi: 10.5753/cbie.wcbie.2016 [GS Search]

CIEB. (2018). Currículo de Referência em Tecnologia e Computação. Centro de Inovação para a Educação Brasileira. Disponível em: http://curriculo.cieb.net.br/.

De Paula, B. H., Valente, J. A., \& Burn, A. (2014). O uso de jogos digitais para o desenvolvimento do currículo para a Educação Computacional na Inglaterra. Currículo sem Fronteiras, 14(3), 46-71. [GS Search]

DOU. (2020). Base Nacional Comum para a Formação Continuada de Professores da Educação Básica. Diário Oficial da União. Disponível em: https://www.in.gov.br/web/dou/-/resolucaocne/cp-n-1-de-27-de-outubro-de-2020-285609724

DOU. (2021). Política de Inovação Educação Conectada. Diário Oficial da União. Disponível em: https://www.in.gov.br/en/web/dou/-/lei-n-14.180-de-1-de-julho-de-2021-329472130

Giannakos, M. N., Krogstie, J., \& Chrisochoides, N. (2014). Reviewing the flipped classroom research: reflections for computer science education. Proceedings of the computer science education research conference, 23-29. doi: 10.1145/2691352.2691354 [GS Search]

Gil, A. C. (2008). Métodos e técnicas de pesquisa social. $6^{\mathrm{a}}$ ed. Editora Atlas.

Grover, S., \& Pea, R. (2013). Pensamento computacional em K-12: Uma revisão do estado do campo. Pesquisador educacional, 42(1), 38-43. [GS Search]

Kretzer, F. M. (2019). Desenvolvimento de uma Unidade Instrucional para Formação de Professores da Educação Básica para o Ensino de Computação. Disponível em: https://repositorio.ufsc.br/handle/123456789/202658 [GS Search]

Lévy, P. (2007). Inteligência coletiva (A). Edições Loyola.

Mandaji, M., Kelly Da Silva, R., Aparecida de Lima Terçariol, A., \& Luis Mazurkievicz, G. (2018). O Programaê! E a Formação de Professores para a Integração do Pensamento Computacional ao Currículo. Ciet: Enped. Disponível em: https://cietenped.ufscar.br/submissao/index.php/2018/article/view/613 [GS Search]

MEC. (2017). Base Nacional Comum Curricular. Ministério da Educação. Disponível em: http://basenacionalcomum.mec.gov.br/.

MEC. (2018). Programa de Inovação Educação Conectada. Ministério da Educação. Disponível em: http://educacaoconectada.mec.gov.br/.

Mishra, P., \& Koehler, M. J. (2006). Technological Pedagogical Content Knowledge: A Framework For Teacher Knowledge. Teachers College Record, 108(6), 1017-1054. [GS Search]

Morin, E. (2020). Os sete saberes necessários. Rio de Janeiro: Bertrand Brasil.

Nuñez, I. B., Ramalho, B. L., \& Uehara, F. M. G. (2009). As Teorias Implícitas sobre a aprendizagem de professores que ensinam Ciências Naturais e futuros professores em formação: a formação faz diferença?. Ciências \& Cognição, 14(3), 39-61. [GS Search]

Papert, S. (1994). A máquina das crianças. Porto Alegre: Artmed, 17.

Prensky, M. (2001). Nativos digitais, imigrantes digitais. On the horizon, 9(5), 1-6. [GS Search]

Raabe, A. L. A., Gomes, A. S., Bittencourt, I. I., \& Pontual, T. (2016). Educação criativa: multiplicando experiências para a aprendizagem. Pipa Comunicação. 
Ramalho, B. L. (2014). Formação, representações e saberes docentes: elementos para se pensar a profissionalização dos professores. Mercado de letras.

Rocha, A. K. O., \& Prado, M. E. B. B. (2018). A Programação Computacional Desenvolvida na Perspectiva do Tpack no Contexto da Formação Continuada do Professor de Matemática. Jornal Internacional de Estudos em Educação Matemática, 11(3), 202-209. doi: 10.17921/2176-5634.2018v11n3p202-209 [GS Search]

Resnick, M. (2020). Jardim de infância para a vida toda: por uma aprendizagem criativa, mão na massa e relevante para todos. Mitchel Resnick; tradução: Mariana Casetto Cruz, Lívia Rulli Sobral; Revisão Técnica: Carolina Rodeghiero, Leo Burd. Porto Alegre: Penso.

SBC. (2017). Diretrizes para o Ensino de Computação na Educação Básica. Sociedade Brasileira de Computação. Disponível em: https://www.sbc.org.br/educacao/diretrizes-para-ensino-decomputacao-na-educacao-basica.

Silva, V., Silva, K., \& França, R. (2017). Pensamento computacional na formação de professores: experiências e desafios encontrados no ensino da computação em escolas públicas. Anais do Workshop de Informática na Escola, 23(1), 805-814. doi: 10.5753/cbie.wie.2017.805 [GS Search]

Valente, J. A. (2016). Integração do pensamento computacional no currículo da educação básica: diferentes estratégias usadas e questões de formação de professores e avaliação do aluno. Revista E-curriculum, 14(3), 864-897. [GS Search]

Valente, J. A. (1997). O uso inteligente do computador na educação. Revista Pátio, 1(1), 19-21. [GS Search]

Valente, J. A. (2019). Pensamento computacional, letramento computacional ou competência digital? Novos desafios da educação. Revista educação e cultura contemporânea, 16(43), 147-168. [GS Search]

WEF. (2020). The Future of Jobs Report 2020. World Economic Forum. Disponível em: https://www.weforum.org/reports/the-future-of-jobs-report-2020.

Wing, J. (2006). Computational Thinking. Communications of the ACM, 49(3). doi: $\underline{10.1145 / 1118178.1118215}$ [GS Search]

Zanetti, H., \& Oliveira, C. (2015). Práticas de ensino de Programação de Computadores com Robótica Pedagógica e aplicação de Pensamento Computacional. Anais dos Workshops do Congresso Brasileiro de Informática na Educação, 4(1), 1236-1245. doi: $\underline{10.5753 / \text { cbie.wcbie.2015.1236 [GS Search] }}$ 